\title{
Utility of Transesophageal Echocardiography During Severe Hypotension in Non-cardiac Surgery
}

\author{
Cabrera Schulmeyer ${ }^{1}$, Jorge Farías ${ }^{1}$, Eduardo Rajdl ${ }^{1}$, Jaime de La Maza ${ }^{1}$, Marcela Labbé ${ }^{1}$
}

\begin{abstract}
Summary: Schulmeyer C, Farías J, Rajdl E, Maza J, Labbé M - Utility of Transesophageal Echocardiography During Severe Hypotension in Non-cardiac Surgery.
\end{abstract}

Background and objectives: Severe and refractory hypotension is an infrequent perioperative situation during non-cardiac surgery, but determining its etiology is essential for successful management and therapy.

Methods: Adults undergoing non-cardiac surgery were prospectively enrolled in this study. Severe hypotension was defined as a drop from $30 \%$ of baseline systolic arterial pressure unresponsive to adequate fluids administration and to ephedrine, according to the anasthesiologist criteria. A multiplanar transesophageal echocardiography (TEE) probe was inserted, prior to any other invasive hemodynamic monitor.

Results: Forty two adults (68 \pm 12 years) were studied, $84 \%$ during elective non-cardiac surgery. Abdominal (open and laparoscopic), thoracic and orthopaedic surgeries were performed most frequently. In all patients, TEE was useful for determining the etiology of severe hypotension. Hypovolemia was diagnosed in 18 patients (42\%). Low ejection fraction (EF < 30\%) was detected in 5 cases and was successfully treated with vasoactive drugs. Dynamic left ventricular outflow tract obstruction, associated with systolic anterior motion of the mitral valve, was diagnosed in 5 patients; in another 6 patients severe embolism was detected during hip and knee surgery. Myocardial ischemia causing persistent hypotension was detected in 5 patients; in 3 patients, cardiac tamponade was the etiology of severe hypotension. Two patients died; both had severe myocardial ischemia.

Conclusions: Perioperative TEE was performed quickly, proving to be a useful technique in the context of hypotension during non-cardiac surgery. The heart and great vessels could be observed directly and functionally evaluated. Thus, the etiology of severe hypotension could be easily determined and managed.

Keywords: COMPLICATIONS: arterial hipotension; MONITORING: transesophageal echocardiography.

Financial Suport: This work was supported by the Air Force Hospital and University of Valparaiso, the source of funding for this study was the Air Force Hospital of Santiago de Chile. There are no conflicts of interest to disclose.

[Rev Bras Anestesiol 2010;60(5): 513-521] @Elsevier Editora Ltda.

\section{INTRODUCTION}

Intraoperative transesophageal echocardiography (TEE) is an important improvement in cardiovascular monitoring for complex cardiac patients ${ }^{1-4}$.

According to the guidelines established by the American Society of Anesthesiologists 5,6, TEE should be used when unexplained life-threatening circulatory instability persists despite corrective therapy, this indicates that there is evidence or general agreement that TEE is useful and effective 7,8 . Hypotension is one of the most common perioperative complications during general anesthesia. It may significantly increase perioperative morbidity and mortality and contribute to adverse postoperative

Received from Fach Hospital, Universidad de Valparaíso, Santiago, Chile.

1. MD, Anesthesiologist.

Submitted on March 5, 2010

Approved on May 16, 2010.

Correspondence to:

Dra. María Carolina Cabrera Schulmeyer

Fernández Mira 796

Las Condes

Santiago, Chile

Phone: 56 (2) 7826164, Fax: 56 (2) 7826170

E-mail:carol218@vtr.net outcomes ${ }^{9,10}$. Drugs, anesthesia-mediated vasodilation and hypovolemia represent the most common pathogenic mechanisms. However, anesthesiologists infrequently encounter severe and persistent hypotension in a patient who has been adequately volume- and drug-managed. Such a situation demands the placement of an arterial line, a central venous or pulmonary artery catheter. The process is time-consuming and carries known risks. Another important consideration is the poor correlation between ventricular filling pressures and ventricular volume because of variability in ventricular compliance observed in elderly patients, in patients with myocardial damage, in patients with septic shock, and even in normal subjects. We designed a prospective protocol for using TEE during non-cardiac surgery as first hemodynamic monitor installed to determine the etiology of severe hypotension. The aim of the study was to evaluate the clinical utility of TEE in assessing patients who were acutely hemodynamic unstable in the operating room during noncardiac surgery.

\section{METHODS}

The study was approved by the local Ethics Committee. Adult patients undergoing non-cardiac surgery with standard non- 
invasive monitoring ( $\mathrm{SpO}_{2}$, ECG, NIBP) and suffering from severe and refractory hypotension, were studied between March 2007 and December 2009. Patients with arterial line, central venous catheter or patients with a pulmonary artery catheter installed at the beginning of the surgery were excluded and patients with severe esophageal or gastric disease were excluded, too. All patients were under general anesthesia and the trachea was intubated.

Blood pressure was assessed every 2.5 min using a noninvasive monitor standardised for patient size. Refractory intraoperative hypotension was defined as a drop from $30 \%$ of baseline of systolic arterial pressure lasting for at least five minutes and unresponsive to adequate volume replacement and ephedrine IV boluses (6mg each), and according to the anesthesiologist criteria. Then the attending anesthesiologist as the first action, before installing any other invasive hemodynamic monitor, asked a TEE-competent anesthesiologist to perform the exam (a TEE-competent anaesthesiologist was available at all times). Thus all TEE exams were performed by an anesthesiologist with advanced training, who was present for the remainder of the surgery to answer any questions posed by the anesthesiologist conducting the anesthesia. TEE was performed using a multiplane phased array probe $5 \mathrm{Mhz}$ (Hewlett Packard Sonos 5000 and a Sonosite Micromaxx). All images were recorded and a written report was attached to the patients' clinical records.

After the probe was inserted, the TEE images were rapidly evaluated, in an effort to identify the cause of the hypotension. Several images were obtained for every patient, including: the four-chamber view (Figure 1), the long and short axis view of aortic valve and ascending aorta; and the transgastric short axis view of the left and right ventricles (Figure 2). On average, obtaining the TEE information took 3 minutes. Normal LV end-systolic volume (LVESV) was considered when $<35 \mathrm{~mL}$ to $>55 \mathrm{~mL}$ and LV end-diastolic volume (LVEDV) $<65 \mathrm{~mL}$ to $95 \mathrm{~mL}$, according with guidelines for standard LV measurement.

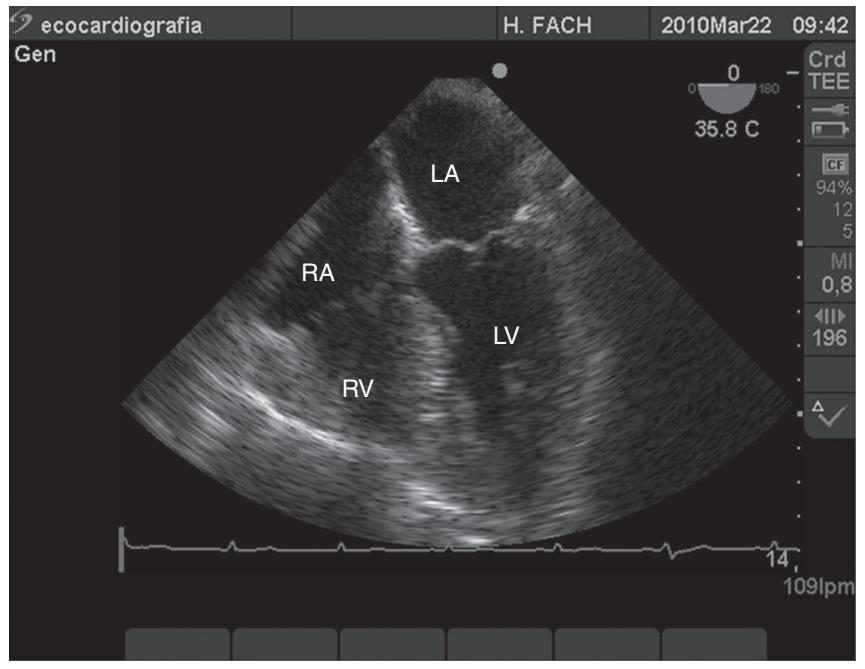

Figure 1. Four Chamber View, $R A=$ right atrium, $R V$ = right ventricle, $L A=$ left atrium, $L V=$ left ventricle.

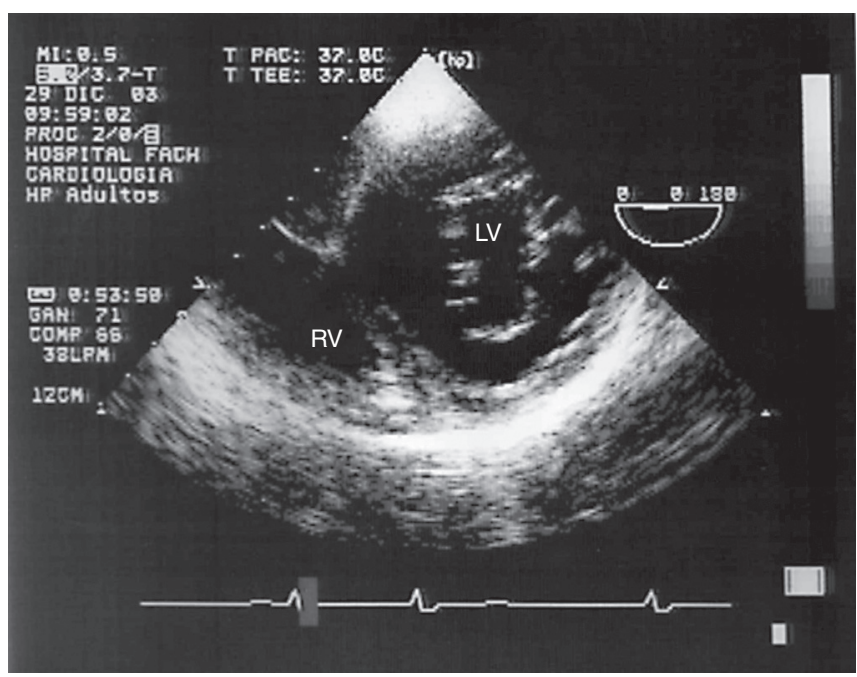

Figure 2. Transgastric Short Axis View, RV = right ventricle, LV = left ventricle.

The formula used to calculate the ejection fraction (EF, \%) was:

$$
\text { LVEF }=(\text { LVEDV }- \text { LVESV) } / \text { LVEDV } \times 100
$$

LV volumes were assessed using the Simpson's rule of discs included in the TEE machine's software. Normal value of EF was considered $\geq 50 \%$, mild disfunction $30-40 \%$ and severe disfunction $<30 \%$.

For identification of myocardial ischemia images in the left ventricle short and long axis were divided into 17 segments. Each segment was inspected to evaluate wall thickening and motion (normal, mild hypokinesis, severe hypokinesis, akinesis and dyskinesis). The worsening of wall motion was defined as a new episode suggestive of ischemia.

Mitral, Aortic and tricuspid valves were assessed with color, pulsed and continuous doppler.

\section{Statistical analysis}

All statistical analysis were performed using commercially available software STATA 10.0 (stat view State Corp LP, 4905 Lakeway Drive,College Station, Texas 77845 USA.,). Data are presented as mean (SD) and percentages (\%).

\section{RESULTS}

From March 2007 to December 2009, 22,355 patients underwent non cardiac surgery in the Hospital. Among these, 42 patients who developed intraoperative severe and refractory hypotension with standard non invasive monitoring were studied. No patient was excluded on the basis of TEE transducer unavailability. One patient was excluded because of recent esophageal surgery.

Twenty two males and 20 females (mean age of $68 \pm 12$ years) undergoing non-cardiac surgery were monitored with TEE (abdominal surgery 22 patients (52\%), orthopedics 10 patients (23\%); gynecologic 6 patients (12\%) and thoracic 
4 cases $(9 \%))$. ASA I, 4 patients (9\%); ASA II, 23 patients (54\%); and ASA III, 15 patients (36\%) constituted this group. Eighty six percent of cases (36 patients) represented elective surgery; six represented emergency surgeries (Table I).

In all patients, TEE was useful for determining the etiology of severe hypotension. It was also useful as a cardiovascular monitor, for guiding volume replacement and drug therapy. In $25(60 \%)$ patients there was no need for further invasive cardiovascular monitoring (e.g., arterial line, central line or pulmonary artery catheter). An arterial line was installed in 8 cases to accommodate frequent laboratory tests and to facilitate postoperative monitoring. In 10 patients, a central line was installed for administering vasoactive drugs, but not for monitoring CVP. In the postoperative period, 2 patients required a pulmonary artery catheter because of renal failure (1 case) and pulmonary edema (1 case).

Hypovolemia was the most frequent diagnosis recorded in patients (18 patients, 42\%). Low systolic and diastolic volumes of the left and right ventricle were measured, visible at the fourchambers and transgastric views. Poor ejection fraction $(E F<$ $30 \%$ ) was detected in 5 patients and successfully treated, with vasoactive drugs (dobutamine infusion at $5 \mu \mathrm{gg}^{\mathrm{kg}}{ }^{-1}$ ) improving the EF by at least $10 \%$, without any new segmental wall motion abnormality. Embolic phenomena were observed in 6 cases; in all patients, the echocardiographic images revealed significant embolic material seen in the right atrium, right ventricle and in the pulmonary artery sufficient to compromise hemodynamics as well as dilation and hypertension of RV cavities (Figure 3).

Defects of segmental wall motion were observed in 5 patients. Three of these cases also exhibited an ECG alteration. One case presented with ST changes, one with ventricular tachycardia and one with ventricular fibrillation. Two of these patients died in the operating room. The remaining three patients underwent successful perioperative medical management of their ischemic pathology, based on nitroglycerin in-

Table I - Demographic Data, American Society of Anesthesiologists (ASA) Classification and Type of Surgery for Patients with Intraoperative Severe Hypotension

\begin{tabular}{ll}
\hline $\mathrm{n}$ & 42 \\
\hline gender & 22 males / 20 females \\
age (year) & $67 \pm 11$ \\
height (cm) & $164 \pm 14$ \\
weight $(\mathrm{kg})$ & $68 \pm 11$ \\
ASA I & $4(9 \%)$ \\
ASA II & $23(50 \%)$ \\
ASA III & $15(35 \%)$ \\
Elective surgery & $36(84 \%)$ \\
Laparoscopic cholecistecthomy & 9 \\
Open hemicoledomy & 4 \\
Laparoscopic hemicoledomy & 3 \\
Hip surgery & 7 \\
Kne e surgery & 3 \\
Thoracic surgery & 4 \\
Neurosurgery & 2 \\
Gynecologyc surgery & 2 \\
Spine surgery & 2 \\
Emergency surgery & $6(16 \%)$ \\
\hline
\end{tabular}

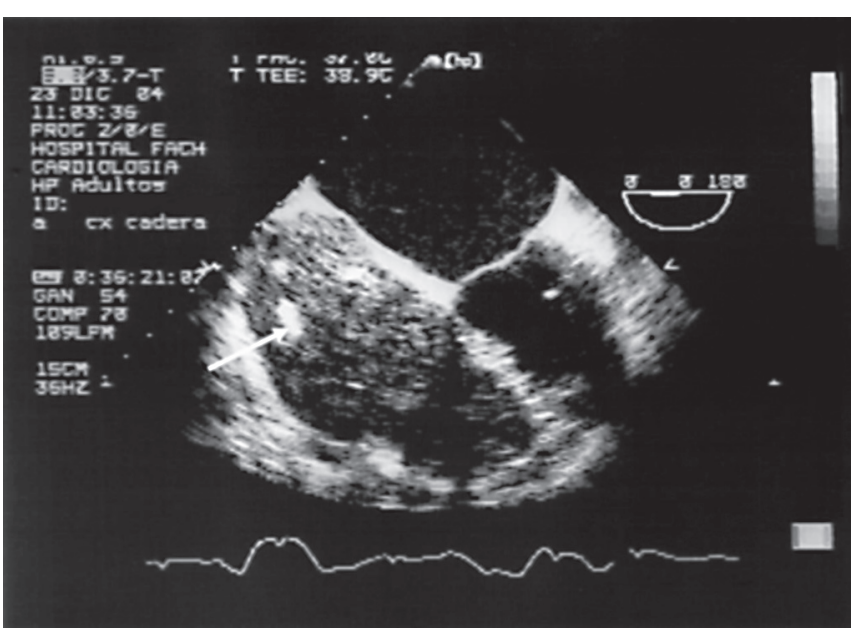

Figure 3. Embolic Phenomena. White arrow shows embolic material in the right atrium.

fusion (1-5 $\mu \mathrm{g} \cdot \mathrm{kg}^{-1}$ ), betablocker (one patient with normal EF) and anticoagulants (as soon as the surgeon allowed). On the second postoperative day, one patient required an emergency coronary angiography and underwent successful right coronary angioplasty without stent installation.

Dynamic left ventricular outflow tract obstruction associated with systolic anterior wall motion (SAM) of the mitral valve was an unexpected frequent cause of severe intraoperative hypotension (detected in 5 patients). Only two of these patients had a past history of hypertension and none of them had left ventricular hypertrophy. All patients exhibited mitral regurgitation and were not receiving vasoactive therapy at the time of the diagnosis. Two of the cases were also hypovolemic with low LV end-diastolic diameters. Fluid reposition and betablockers, the first line drugs selected, allowed good results.

Pericardial effusion was the primary cause of severe intraoperative hypotension in 3 patients. One of these cases was a female undergoing a large gynecologic intervention. She presented low $\mathrm{SpO}_{2}$ and severe hypotension, unresponsive to volume treatment. After the examination with TEE, a pericardial effusion was detected (that was not present in the preoperative transthoracic examination); after drainage, arterial pressure returned to normal values. The two other patients were diabetic type II patients with abdominal sepsis, from the ICU. The installation of drainage resulted in the return of hemodynamic parameters to normal values in these patients.

No complications were observed following the use of intraoperative TEE.

\section{DISCUSSION}

Transesophageal echocardiography was helpful in $100 \%$ of the 42 cases evaluated for severe intraoperative episodes of hypotension during non-cardiac surgery. In this clinical scenario of patients monitored with standard non invasive monitoring devices, TEE permits an anatomic and functional diagnosis, quickly and 
in a semi-invasive way. The images obtained were also useful for guiding treatment. Prompt diagnosis with TEE not only clarified the possible etiology but also facilitated the rapid initiation of therapeutic intervention. Analysing the study results, it is clear that hypovolemia was the most frequent cause of intraoperative hypotension. Based on the inclusion criteria of the study, the anesthesiologist ensured the patient had been adequately volume resuscitated with a correct fluid balance prior to performing the TEE. Maybe this incorrect estimation is a result of an unmeasurable third space formation.

Myocardial ischemia was not a frequent cause of intraoperative hypotension in our study (5/38). However, hypotension present secondary to ischemia resulted in a poor prognosis. This poor prognosis may result from the magnitude of the ischemic event: if it compromised hemodynamic function, it was certainly a massive ischemic event.

Embolic phenomena were diagnosed during orthopaedic surgery and were enough to produce severe hypotension. Embolic material of different sizes filled right cavities and pulmonary artery, severely altering contractility. In these patients, TEE was useful not only for the diagnosis of embolic events, but also for the differential diagnosis of other causes of hypotension during orthopedic surgery (like hypovolemia or myocardial ischemia).

Abundant evidence has demonstrated that TEE is the best intraoperative monitor for detecting embolic events, permitting the modification of the therapeutic regimen 11,12,13.

Dynamic left ventricular outflow tract (LVOT) obstruction associated with systolic anterior movement of the mitral valve (SAM) is a phenomenon rarely encountered by non-cardiovascular anaesthesiologists. Luckner et al ${ }^{14}$ published a clinical series of three cases of SAM during non-cardiac surgery as proof of the etiology of hypotension. If TEE is performed more frequently during non-cardiac surgery, maybe these diagnoses will become more frequent.

SAM during non-cardiac surgery is a different clinical entity than SAM that appears after a mitral annuloplasty or mitral reparation. SAM during non-cardiac surgery has been associated with predisposing features like a past history of hypertension and myocardial hypertrophic cardiomyopathy. SAM has also been associated with hypovolemia, generating a hypercontractile left ventricle and resulting in rapid blood flow velocities in the outflow tract. Thus, parts of the anteriorly displaced mitral valve leaflets extend past their coaption point and protrude into the rapid velocity flow of the left ventricular outflow tract. Could SAM be the last stage of hypovolemia? The answer requires investigation in the context of non-cardiac surgery.

It is important that the majority of patients during this study had no further cardiovascular invasive monitoring; TEE provided sufficient information for the diagnosis and cardiovascular management of the patient.

Brandt et al ${ }^{15}$, studied the role of emergency intraoperative echocardiography in 66 patients. They recommended that TEE should be considered as the diagnostic tool of choice when surgical patients had unexplained hemodynamic instability during cardiac $(n=46)$ and non-cardiac $(n=20)$ surgery.

Denault and Couture ${ }^{16}$, in a retrospective study of 214 noncardiac surgery and ICU patients, demonstrated the utility of
TEE for management adjustments necessary to modify medical therapy. Kolev ${ }^{17}$ studied the influence of TEE on intraoperative decision-making using the ASA guidelines. This study included 224 patients, undergoing cardiac and non-cardiac surgery. Their observations resulted in a $30 \%$ change in overall management, with a greater impact in category I than category II indications.

Limitations of this study include first the definition of severe hypotension. It was very difficult to find definitive parameters for which all anesthesiologists were in agreement, so we decided upon the drop from $30 \%$ of systolic blood pressure. Nonetheless, the subjective evaluation and judgment of the anesthesiologist in charge of the patient determined whether TEE was requested in the operating room. Second, a comparison with other monitoring modalities would have aided in proving the effectiveness and usefulness of TEE in non-cardiac surgery. Such a comparison was not performed in this study, because the aim was to evaluate if TEE could be useful as a first choice monitor for diagnosing and treating a patient with refractory hypotension. Hypotension was attributed in every subject to some echocardiographic abnormality, but we considered that low systemic vascular resistance (which is not estimated by TEE) could have been a contributing factor. One main cause or finding per patient was stated. If a patient had pump failure secondary to ischemia, this was categorized as ischemia. It is difficult to ascertain if an abnormal finding is causing hemodynamic instability unless it is severe or represents a new change. The study was not designed to pick up new changes but rather take a snapshot when the patient was already hypotensive. The lack of a control group prevents the determination of the independent impact of TEE on the outcome in these patients. Furthermore, identifying a matched group of historical controls may be extraordinarily difficult, given the relative infrequency of severe intraoperative hypotension and the multitude of conflicting variables that may impact on the outcome after severe intraoperative hypotension. Because of the rather small number of patients, this analysis does not address postoperative outcome parameters, like morbidity and mortality. Finally another critical issue is the lack of any information on preoperative evaluation. TEE is effective to help anaesthesiologist when an intraoperative hypotension arise, but must be not recommended to replace the lack of preoperative screening. The use of routine TEE is now validated according to the ASA guidelines and now there is general agreement that TEE should be used for noncardiac surgical patients when the patient has known or suspected cardiovascular pathology that might result in hemodynamic, pulmonary, or neurologic compromise.

In conclusion, considering the limitations of this study, TEE was a very useful cardiovascular monitoring tool for diagnosing the etiology of intraoperative severe hypotension. TEE is currently the most important imaging tool available for anesthesiologists in the operating room, thus its indications and benefits need to be thoroughly explored in the non-cardiac surgery patient. The advantages of TEE should be weighed against the costs and expertise required. However, if available in the operating room and a trained anesthesiologist can perform the examination, TEE should be used as a first choice monitoring tool during a severe hemodynamic event. 
10. Monk T, Saini V, Weldon B et al - Anesthesic Management and one-year mortality after non-cardiac surgery. Anesth Analg, 2005;100:4-10.

11. Rosenberg $P$, Stanton S, Body S et al - Utility of intraoperative Transesophageal echocardiography for diagnosis of pulmonary embolism. Anesth Analg, 2004;99:12-16.

12. Koessler M, Fabiani R, Hamer $\mathrm{H}$ et al - The clinical relevance of embolic events detected by transesophageal echocardiography during cemented total hip artroplasty: a randomized clinical trial. Anesth Analg, 2001;92:49-55.

13. Fallon K, Fuller J, Monley $\mathrm{P}$ - Fat embolization and fatal cardiac arrest during hip artroplasty with methylmethacrylate. Can J Anaesth, 2001;48:626-629.

14. Luckner G, Margreiter J, Jochberger S et al. - Systolic anterior motion of the mitral valve with left ventricular outflow tract obstruction: three cases of acute perioperative hypotension in non-cardiac surgery. Anesth Analg, 2005;100:1594-1598.

15. Brandt RR, Oh JK, Abel MD et al - Role of emergency intraoperative transesophageal echocardiography. J Am Soc Echocardiogr, 1998;11:972-977.

16. Denault AY, Couture P, McKenty $S$ et al. - Perioperative use of transesophageal echocardiography by anesthesiologists: impact in non-cardiac surgery and in the intensive care unit. Can $J$ Anesth, 2002;40:287-293.

17. Kolev N, Brase R, Swanevelder J et al. - The influence of transoesophageal echocardiography on intra-operative decision making. A European multicentre study. European Perioperative TOE Research Group. Anaesthesia, 1998;53:767-773

\section{REFERÊNCIAS / REFERENCES}

01. Mishra M, Chauhan R, Sharma KK et al. - Real-time intraoperative transesophageal echocardiography: how useful? Experience of 5,016 cases. J Cardiothorac Vasc Anesth, 1998;12:625-632.

02. Fanshawe M, Ellis C, Habib S, Konstadt S, Reich D - A Retrospective Analysis of the Costs and Benefits Related to Alterations in Cardiac Surgery from Routine Intraoperative Transesophageal Echocardiography. Anesth Analg, 2002;95:824-827.

03. Hofer C, Zollinger A, Rak M et al. - Therapeutic impact of intra-operative Transesophageal echocardiography during non-cardiac surgery. Anaesthesia, 2004;59:3-9.

04. Patteril M, Swaminathan M - Pro: intraoperative transesophageal echocardiography is of utility in patients at high risk of adverse cardiac events undergoing non-cardiac surgery. J Cardiothorac Vasc Anesth, 2004; 18:107-109.

05. Practice guidelines for perioperative transesophageal echocardiography. A report by the American Society of Anesthesiologists and the Society of Cardiovascular Anesthesiologists Task Force on Transesophageal Echocardiography. Anesthesiology, 1996;84:986-1006.

06. American Society of Anesthesiologists and Society of Cardiovascular Anesthesiologists Task Force on Transesophageal Echocardiography. - Practice guidelines for perioperative transesophageal echocardiography. Anesthesiology, 2010;112:1-13.

07. Suriani RJ, Neustein S, Shore-Lesserson L, Konstadt S - Intraoperative transesophageal echocardiography during non-cardiac surgery. J CardioThorac Vasc Anesth, 1998;12:274-280.

08. Couture P, Denault AY, McKenty S et al. - Impact of routine use of intraoperative transesophageal echocardiography during cardiac surgery. Can J Anesth, 2000;47:20-26.

09. Reich D, Hossain S, Krol M et al. - Predictors of hypotension alter induction of general anesthesia. Anesth Analg, 2005;101:622-628.

Revista Brasileira de Anestesiologia

Resumen: Schulmeyer CC, Farías J, Rajdl E, Maza J, Labbé M Utilidad de la Ecocardiografía Transeofageana durante Hipotensión Arterial Severa en Cirugía no Cardiaca.

Justificativa y objetivos: La hipotensión arterial severa y refractaria es una incidencia rara en Cirugías no cardiacas, pero determinar su etiología es esencial para el tratamiento exitoso.

Métodos: Adultos sometidos a cirugías no cardiacas que fueron incluidos prospectivamente en este estudio. La hipotensión arterial severa fue definida como una caída de un $30 \%$ con relación a la presión arterial sistólica basal que no respondió a la administración adecuada de fluidos y efedrina, de acuerdo con critérios del anestesiólogo. Una sonda multiplanar de ecocardiografía transesofageana (ETE) se insertó antes de cualqueir otro monitoreo hemodinámico invasivo.

Resultados: Cuarenta y dos adultos (68 \pm 12 años) se incluyeron en este estudio, $84 \%$ durante la Cirugía no cardiaca electiva. Cirugías abdominales (abiertas y laparoscópicas), torácicas y ortopédicas fueron las más frecuentes. En todos los pacientes, la ETE fue útil para la determinación de la etiología de la hipotensión arterial severa. La Hipovolemia fue diagnosticada en 18 pacientes (42\%). Una baja fracción de eyección ( $\mathrm{FE}<30 \%$ ), fue detectada en cinco casos, y fue tratada exitosamente con la administración de fármacos vasoactivos. Se diagnosticó la obstrución dinámica de la vía de salida del ventrículo izquierdo asociada al movimento sistólico anterior (MAS), de la válvula mitral en cinco pacientes; en otros seis, fue detectada embolia severa durante cirugía de caderas y rodillas. La Isquemia miocárdica causando hipotensión arterial persistente se detectó en cinco pacientes; en tres pacientes, el taponamiento cardíaco fue la causa de la hipotensión arterial severa. Dos pacientes fallecieron y ambos presentaban isquemia miocárdica severa.

Conclusiones: La Ecocardiografia transesofageana perioperatoria fue realizada rápidamente y demostró ser una técnica útil en el contexto de la hipotensión arterial durante la cirugía no cardiaca. El corazón y los grandes vasos, pudieron ser observados directamente y evaluados de modo funcional. Así, la etiología de la hipotensión arterial severa puede ser fácilmente identificada y tratada. 